\title{
Aberrant ERK 1/2 complex activation and localization in scrapie-infected GT1-1 cells
}

\author{
Alessandro Didonna', Giuseppe Legname $e^{1,2,3^{*}}$
}

\begin{abstract}
Background: Fatal neurodegenerative disorders such as Creutzfeldt-Jakob and Gerstmann-Sträussler-Scheinker diseases in humans, scrapie and bovine spongiform encephalopathy in animals, are characterized by the accumulation in the brain of a pathological form of the prion protein (PrP) denominated $\operatorname{PrP}{ }^{\mathrm{Sc}}$. The latter derives from the host cellular form, PrPC, through a process whereby portions of its $\alpha$-helical and coil structures are refolded into $\beta$-sheet structures.

Results: In this work, the widely known in vitro model of prion replication, hypothalamic GT1-1 cell line, was used to investigate cellular and molecular responses to prion infection. The MAP kinase cascade was dissected to assess the phosphorylation levels of src, MEK 1/2 and ERK 1/2 signaling molecules, both before and after prion infection. Our findings suggest that prion replication leads to a hyper-activation of this pathway. Biochemical analysis was complemented with immunofluorescence studies to map the localization of the ERK complex within the different cellular compartments. We showed how the ERK complex relocates in the cytosol upon prion infection. We correlated these findings with an impairment of cell growth in prion-infected GT1-1 cells as probed by MTT assay. Furthermore, given the persistent urgency in finding compounds able to cure prion infected cells, we tested the effects on the ERK cascade of two molecules known to block prion replication in vitro, quinacrine and Fab D18. We were able to show that while these two compounds possess similar effects in curing prion infection, they affect the MAP kinase cascade differently.

Conclusions: Taken together, our results help shed light on the molecular events involved in neurodegeneration and neuronal loss in prion infection and replication. In particular, the combination of chronic activation and aberrant localization of the ERK complex may lead to a lack of essential neuroprotective and survival factors. Interestingly, these data seem to define some common traits with other neurodegenerative disorders such as, for example, Alzheimer's disease.
\end{abstract}

\section{Background}

Transmissible spongiform encephalopathies (TSE) or prion diseases, such as Creutzfeldt-Jakob disease, Gerstmann-Sträussler-Scheinker syndrome and fatal familial insomnia in humans, bovine spongiform encephalopathy and scrapie in animals, are a group of incurable neurodegenerative disorders. TSE can manifest as spontaneous, inherited and infectious maladies. These diseases are caused by the accumulation of prions in the central nervous system (CNS).

\footnotetext{
* Correspondence: legname@sissa.it

${ }^{1}$ Laboratory of Prion Biology, Neurobiology Sector, Scuola Internazionale Superiore di Studi Avanzati (SISSA), via Bonomea 265, I-34136 Trieste, Italy Full list of author information is available at the end of the article
}

Prions are novel infectious agents composed solely of a pathological isoform of the prion protein $(\operatorname{PrP}) \operatorname{Pr} \mathrm{P}^{\mathrm{Sc}}$, derived from the host-encoded, cellular form of PrP, $\operatorname{PrP}^{\mathrm{C}}$ [1]. $\operatorname{PrP}^{\mathrm{Sc}}$ accumulation is driven by a conversion event in which $\alpha$-helix and random coiled structures are refolded into $\beta$-sheets [2]. The $\operatorname{PrP}^{C}$ molecule is a membrane glycoprotein highly expressed in neurons and is linked to the outer leaflet of neuronal membranes via glycosylphosphatidylinositol moiety localized in cholesterol-rich domains called "rafts". Despite $\operatorname{PrP}^{C}$ being conserved amongst mammals, its function is still ambiguous and defining the cellular processes involved in prion disease remains one of the main challenges in Prion Biology.
C Biomed Central

ㄷ 2010 Didonna and Legname; licensee BioMed Central Ltd. This is an Open Access article distributed under the terms of the Creative Commons Attribution License (http://creativecommons.org/licenses/by/2.0), which permits unrestricted use, distribution, and reproduction in any medium, provided the original work is properly cited. 
While PrP-null mice $\left(\operatorname{Prnp}^{0 / 0}\right)$ do not show gross phenotypic abnormalities [3], analysis of in vitro models of primary cells derived from $\operatorname{Prnp}^{0 / 0}$ revealed a dysmetabolism of copper and an increased susceptibility to oxidative stress [4], suggesting the involvement of $\operatorname{PrP}^{C}$ in redox homeostasis and in copper uptake within the cell. Additional studies revealed a role for $\operatorname{PrP}^{C}$ in cellular adhesion, showing that $\operatorname{PrP}$ interacts with neural cell adhesion molecules (N-CAMs), laminin and laminin receptor $[5,6]$.

Moreover, $\operatorname{PrP}^{\mathrm{C}}$ can regulate neurite outgrowth [7] and neuroprotection [8] in primary cultures of neurons. These two latter effects rely on the interaction of PrP with stress-inducible protein 1 (ST1) and seem to be mediated by distinct signaling pathways [9]. These different lines of experimental evidence suggest that $\operatorname{PrP}^{C}$ may also transduce signals from the membrane to the nucleus. It has been established that $\operatorname{PrP}^{C}$ mediates activation of cAMP/protein kinase A (PKA) in retinal tissue [10] and activation of protein kinase $C$ (PKC) in embryonic rat hippocampal neurons [7]. Moreover, $\operatorname{PrP}^{\mathrm{C}}$ seems to be involved in regulation of calcium-mediated cellular events [11]; in $\operatorname{Prnp}^{0 / 0}$ mice a decrease of calcium influx via VGCC was found, suggesting a functional interaction with calcium channels on the cell membrane [12]. Furthermore, in prion-infected neuroblastoma cells a decrease in receptor-mediated calcium responses was observed [13]. In addition, $\operatorname{PrP}^{\mathrm{C}}$ has been recently identified as an amyloid- $\beta$-oligomer receptor and it appears to mediate impairment of synaptic plasticity in Alzheimer's disease (AD) [14]. Among others, also mitogen-activated protein kinases (MAPKs) pathways seem to be regulated by $\operatorname{PrP}^{\mathrm{C}}$. These signaling cascades are strongly conserved in eukaryotic cells and modulate molecular events involved in cell differentiation, proliferation and apoptosis, and in gene expression and inflammation [15] processes, whose deregulation plays a crucial role in neurodegenerative diseases such as TSE. All these cascades are composed of three distinct modules: MAP kinases, MAPK kinases and MAPKK kinases. In mammals, four sets of MAPKs are expressed: extracellular signal-related kinases (ERK), Jun-amino terminal kinases (JNK), p38 proteins and ERK5 [16]. These cascades have been observed in several cellular models linked to PrP biology. By mimicking the binding of a cellular interactor by antibody mediated cross-linking, a PrP-dependent fyn activation was observed in 1C11 cells [17]. Using a similar approach, ERK1/2 pathway activation was observed in GT1-7 cells [18]. In monocytes, ERK activation was obtained using PrP fusion protein with a Fc domain [19]. The treatment of hippocampal neurons in culture with either hop/STI1 or hop/STI1230-245 also led to ERK activation [9]. The same results were obtained developing retinal tissues using binding molecules for $\operatorname{PrP}^{\mathrm{C}}$ [10]. Hyper-activation of several MAP kinases was observed in hamster brains infected with $263 \mathrm{~K}$ scrapie strain [20], and elevated levels of the src family kinases were found in an in vitro model and two different in vivo models of prion disease [21]. Recent studies have linked the increased level of phosphorylation of the MAP kinases pathway to a neuroprotective and antiapoptotic effect towards toxicity of $\operatorname{PrP}^{\mathrm{Sc}}$ [22]. In contrast, in a model of prion disease using prion peptide 106-126, the overstimulation of ERK pathway was correlated with oxidative injury in GT1 cells throughout ROS production [23]. According to this model oxidative stress plays a central role in neurodegenerative diseases [24].

In this study we used a neuronal cell model, GT1-1 hypothalamic cell line [25], known to support a sustained prion replication. To investigate cell response to prion infection, we focused on MAP kinases. In particular we dissected the ERK pathway, analyzing the levels of phosphorylation of key molecules such as src, MEK and ERK before and after prion infection, both de novo and chronic. We then mapped the distribution of phospho-ERK within the different cellular compartments in infected and uninfected cells. For the first time we showed how prion infection has the capacity of altering the levels of activation and the cellular localization of the ERK complex, affecting cell proliferation. In addition, cells were treated with Fab D18 [26] and quinacrine [27], two molecules known to cure prion infection in cell culture, and assessed for the extent of phosphorylation activation. Our findings show how the two compounds exert different effects on the ERK pathway, suggesting that the two molecules may interfere with prion infection via different pathways.

\section{Results}

\section{Scrapie infection affects MAP kinases levels in GT1 cells}

In recent years several cell systems permissive to the replication of different mouse-adapted prion strains have been developed [28]. They represent a suitable tool for studying the molecular basis of prion-induced neurodegeneration; their simplicity, in fact, allows to analyze the events occurring during prion pathogenesis much better than in vivo models.

To investigate the response of neurons towards prion infection we chose, as a model of prion replication, an immortalized murine cell line derived from hypothalamic cells either uninfected or chronically infected with RML prion strain (GT1 cells and ScGT1 cells respectively, hereafter). In order to elucidate some of the mechanisms leading to neuronal loss we focused on MAP Kinase pathways, given their pivotal role in cell growth and survival. We dissected one of the pathways, the ERK cascade, and, in particular, we analyzed the src 
family, MEK and ERK kinases. The src family is composed of proteins located at the early stages of the ERK cascade, next to the inner leaflet of the cellular membrane. The MEK1/2 protein complex is the physiological activator of ERK1/2, that, in turn, upon activation, can either enter the nucleus and start the gene expression process, or be retained in the cytoplasm to activate other signaling molecules (Fig. 1).

Total cell extracts from GT1, both uninfected and infected (Fig. 2), were tested for phosphorylation levels of the kinases. In ScGT1 cells, scrapie infection led to a general overstimulation of the ERK cascade. Immunoblot revealed a statistically significant increase of phospho-ERK levels in ScGT1 compared to uninfected cells,

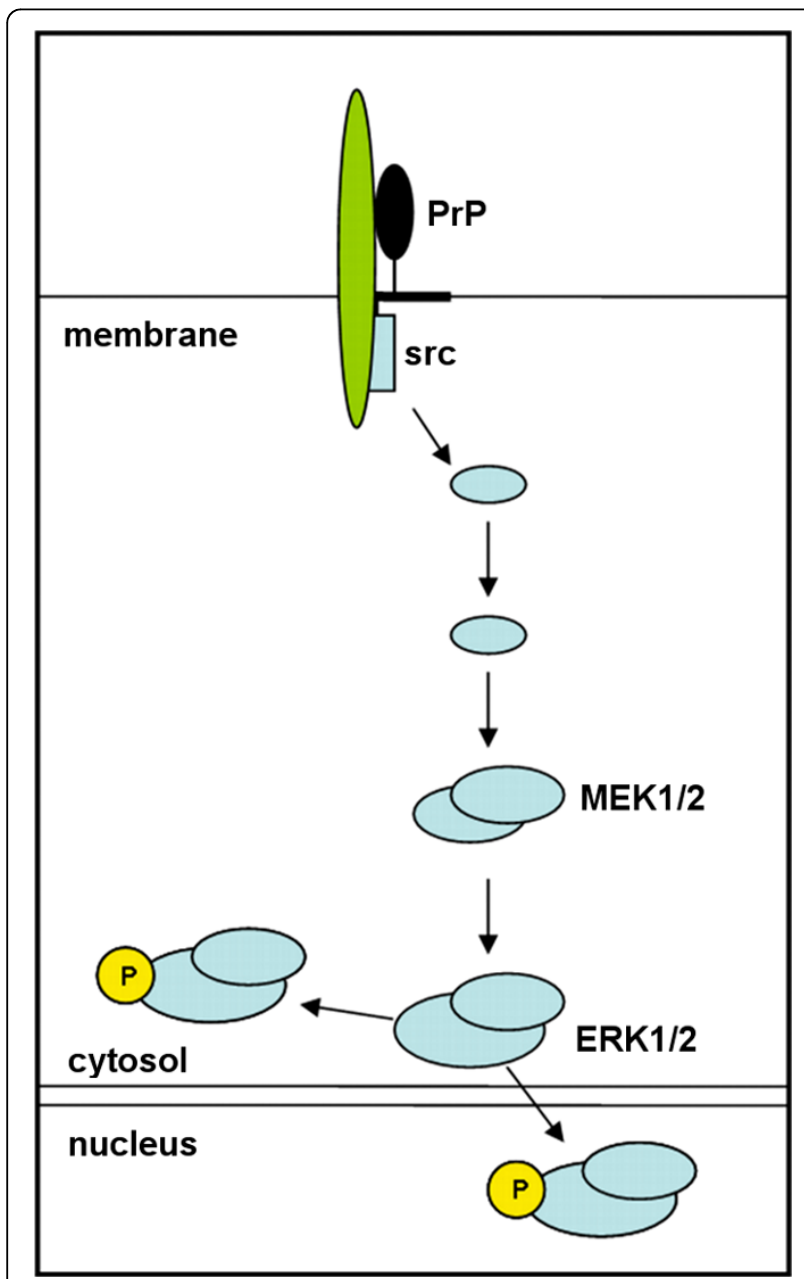

Figure 1 Schematic representation of ERK pathway. $\operatorname{PrP}^{C}$ on the cellular surface assembles a signaling platform with src family proteins. Upon activation, this molecular complex modulates the activity of ERK cascade. Src proteins activate MAP/ERK Kinase 1/2 (MEK1/2). The active forms of MEK1/2 complex can phosphorylize the Extracellular signal-Regulate Kinase 1/2 (ERK1/2) that either enters the nucleus and starts gene expression, or remains within the cytosol.

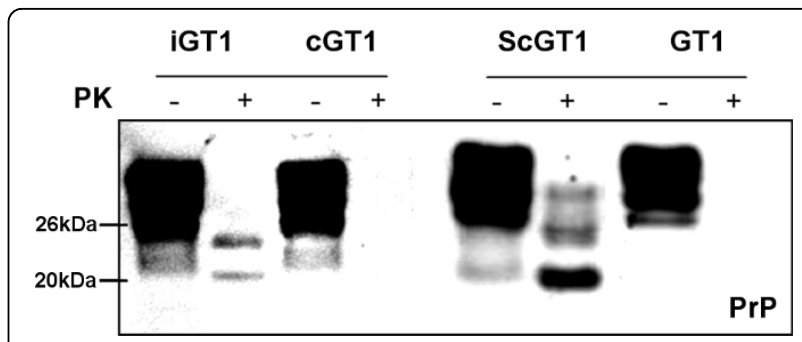

Figure 2 Chronic and de novo infection of GT1 cell line. GT1 cells were infected according to the procedures described in the Materials and Methods section. Regarding de novo infected GT1 cells (iGT1) the presence of PrPsc was tested at the fourth passage. $\mathrm{PrP}^{\mathrm{SC}}$ was detected by PK digestion assay (PK+ lanes) and the signal revealed using Western blot technique. Approximately $20 \mu \mathrm{g}$ of total protein were loaded as control (PK-lanes).

whilst a decrease was detected in the level of phospoMEK upon prion infection (Fig. 3A). Instead, the densitometric analysis between the levels of phospho-src in infected and uninfected cells revealed an increased phospho-src signal in ScGT1 (Fig. 3A).

The activation of ERK pathway was also tested in de novo infected cells. GT1 cells were infected as described in the Materials and Methods section, and tested at the fourth passage upon infection (Fig. 1). De novo infected GT1 cells (iGT1) showed a statistically significant increase of phospho-ERK and phospho-MEK levels compared to mock infected cells (cGT1) (Fig. 3B). On the contrary, the levels of phospho-src were found strongly decreased in iGT1 cells in compared to cGT1 cells (Fig. 3B).

\section{Altered phosphorylation levels upon Fab D18 and quinacrine treatments}

To date an effective cure for prion disease has not been found, although several compounds are known to block prion replication at least in vitro. Considering those as models for the development of new therapeutic strategies, we studied the actions of two of them, Fab D18 and quinacrine, on the ERK pathway in order to evaluate their side effects on cell physiology.

We treated both infected and uninfected cells for six days with Fab D18 at the final concentration of $50 \mathrm{nM}$ and with quinacrine at the concentration of $1 \mu \mathrm{M}$, according to tested concentrations available in the literature $[26,27]$. The $\operatorname{PrP}^{\mathrm{Sc}}$ signal was no longer present in ScGT1 cells after the Fab and drug treatments as ascertained by Western blot (Fig. 4). Next, we analyzed the levels of phosphorylation of src, MEK and ERK kinases, both before and after the treatments.

Following Fab D18 treatment, no significant variations of phospho-ERK levels were found either in ScGT1 or GT1 cells, whereas a significant decrease in D18 treated GT1 was found with regards to phospho-MEK levels 

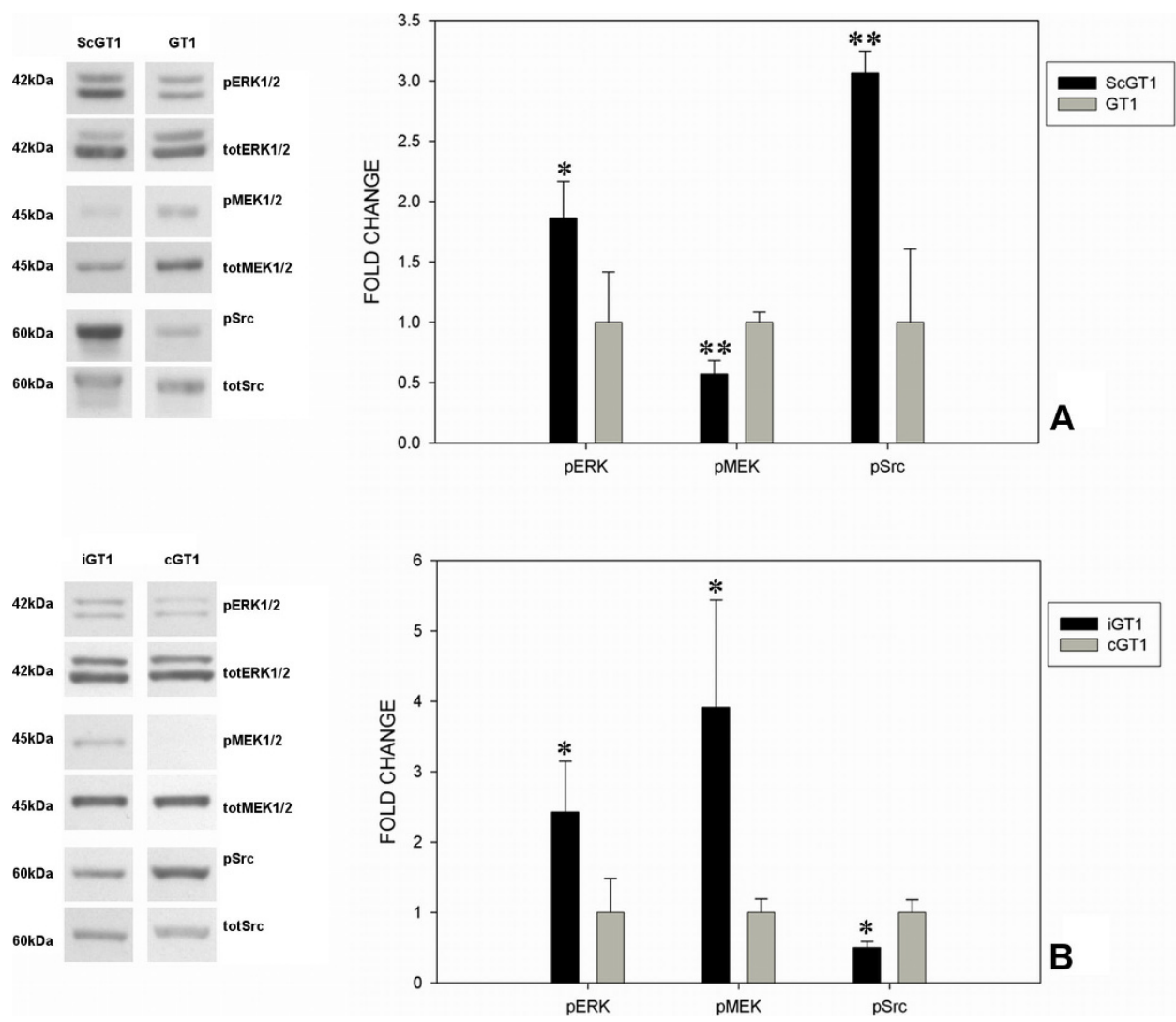

Figure 3 Analysis of ERK pathway in chronic and de novo infected GT1 cells. Approximately $20 \mu \mathrm{g}$ of total proteins were resolved on 12\% polyacrylamide gels to detect the levels of phosphorylated forms of ERK 1/2, MEK 1/2 and src family proteins. The total amount of the same proteins was determined as a control. Prions induced a general hyper-activation of ERK cascade in chronic infected GT1 cells (ScGT1) compared to uninfected cells (GT1). Levels of phospho-ERK and phospho-src proteins increased upon prion infection, whilst a decrease was found in levels of phospho-MEK (panel A). In de novo infected cells (iGT1) the levels of phospho-ERK and phospho-MEK were increased compared to mockinfected ones (CGT1), whilst a decrease of phospho-src was detected upon prion infection (panel B). Statistics were performed using Student's T-test on a set of three independent experiments; data were normalized on the total amount of proteins. ${ }^{*} P<0.05,{ }^{* *} P<0.01$ versus uninfected cells.

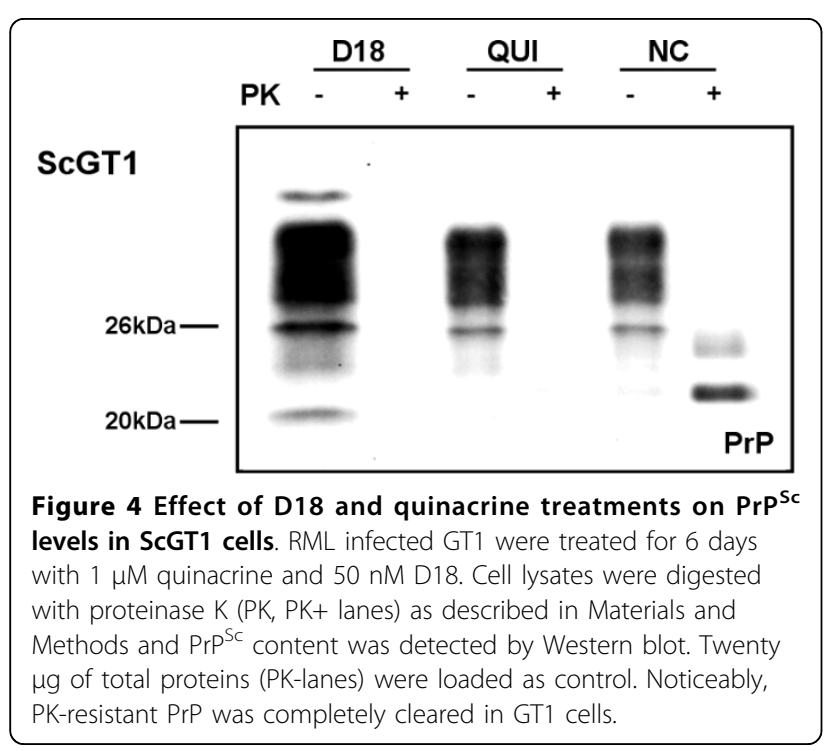

(Fig. 5A). Concerning the src family, incubation with the antibody seemed to significantly decrease the level of phospho-src, both in infected and uninfected GT1 cells (Fig. 5A). Upon quinacrine treatment, the levels of phospho-ERK were unaffected in ScGT1 cells, whilst drug incubation increased the levels of phospho-ERK in noninfected GT1 cells (Fig. 5B). With regards to phosphoMEK levels, quinacrine increased its levels in ScGT1 cells, but not in GT1 (Fig. 5B). Considering the src family activation, levels of phospho-src were strongly decreased in ScGT1 upon quinacrine treatment, whilst the drug was found to have no effect on src family activation in GT1 cells (Fig. 5B).

\section{Cellular localization of phospho-ERK}

When analyzing the action of the ERK pathway, it can be noted that besides being biochemically regulated through the phosphorylation of its kinases, the 

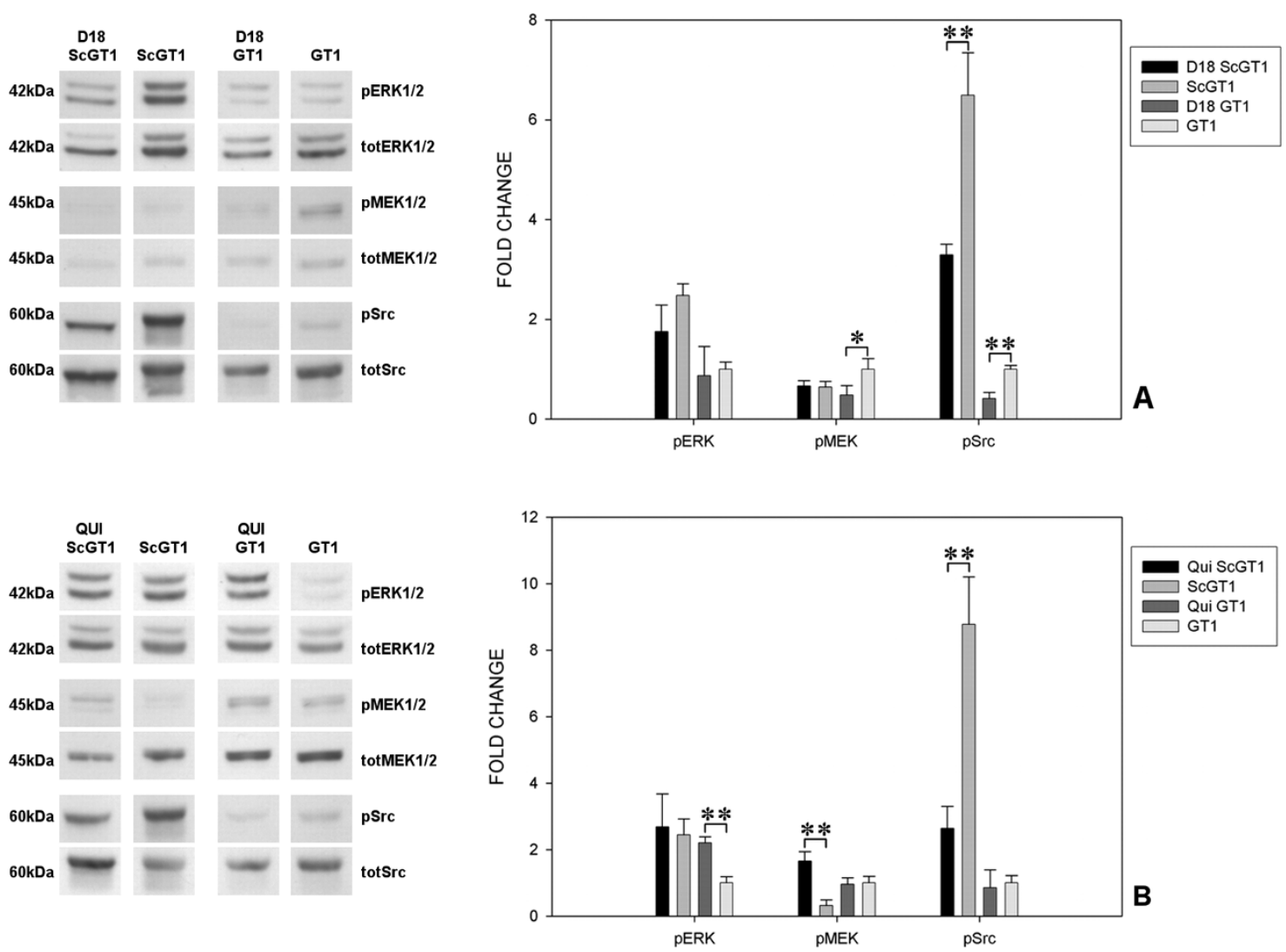

Figure 5 Effect of D18 and quinacrine treatment on ERK pathway in GT1 cells. Infected and uninfected GT1 cells were treated with Fab D18 $(50 \mathrm{nM})$ or quinacrine $(1 \mu \mathrm{M})$ for 6 days; approximately $20 \mu \mathrm{g}$ of total proteins were loaded onto 12\% polyacrylamide gel and assessed for the levels of the phosphorylated forms of ERK $1 / 2$, MEK $1 / 2$ and the src family proteins. The total amount of the same proteins was determined as a control. Fab D18 did not appear to induce any significant changes in the levels of phospho-ERK both in infected and uninfected GT1, whilst decreased levels of phospho-MEK were detected in GT1 cells upon D18 treatment (panel A). Regarding phospho-src proteins, increased levels were found in treated GT1 compared to untreated cells, both infected and uninfected (panel A). On the contrary, quinacrine treatment induces a significant hyper-stimulation of the ERK protein in GT1 cells and even increases the levels of the phospho-MEK in ScGT1 (panel B). Moreover, a strong decrease on phospho-src levels were found in infected GT1 upon drug treatment (panel B). Statistics were performed using Student's Ttest on a set of three independent experiments; data were normalized on the total amount of proteins. ${ }^{*} P<0.05$, ${ }^{* *} P<0.01$ versus untreated controls, both for infected and uninfected cells.

localization of the latter within the different cellular compartments plays a pivotal role in establishing the correct signaling. Upon phosphorylation, in fact, the ERK complex can either be found in the nucleus, or selectively retained within the cytosol. We therefore mapped the cellular distribution of phospho-ERK by means of immunocytofluorescence, aiming at further elucidating the various mechanisms occurring in prioninfected cells.

Both chronically infected, and uninfected, D18 and quinacrine treated and untreated cell lines, were fixed and stained according to the procedures in the Materials and Methods section, and phospho-ERK localization was investigated by confocal microscopy.

The pattern of phospho-ERK distribution for ScGT1 consisted in a granular dispersion of punctuate labeling localized within the cytoplasm, more pronounced in the perinuclear area, whilst in GT1 cells phospho-ERK staining was equally divided between the cytosol and the nucleus (Fig. 6A). The treatment with both Fab D18 and quinacrine seemed to increase the fraction of phosphoERK localized in the nuclear compartment in treated ScGT1 (Fig. 6A), while an opposite effect was detected in treated uninfected GT1cells (Fig. 6A). Statistical analysis was carried out as described in the Materials and Methods section (Fig. 6B).

\section{Prion infection affects cell proliferation}

As ERK cascade is involved in cell growth and survival; in order to correlate the molecular findings about aberrant signaling with defined physiologic effects, the cell proliferation for both ScGT1 and GT1 was monitored before and after the treatment with Fab D18 and quinacrine by means of MTT assay. Without treatment a $40 \%$ lower 


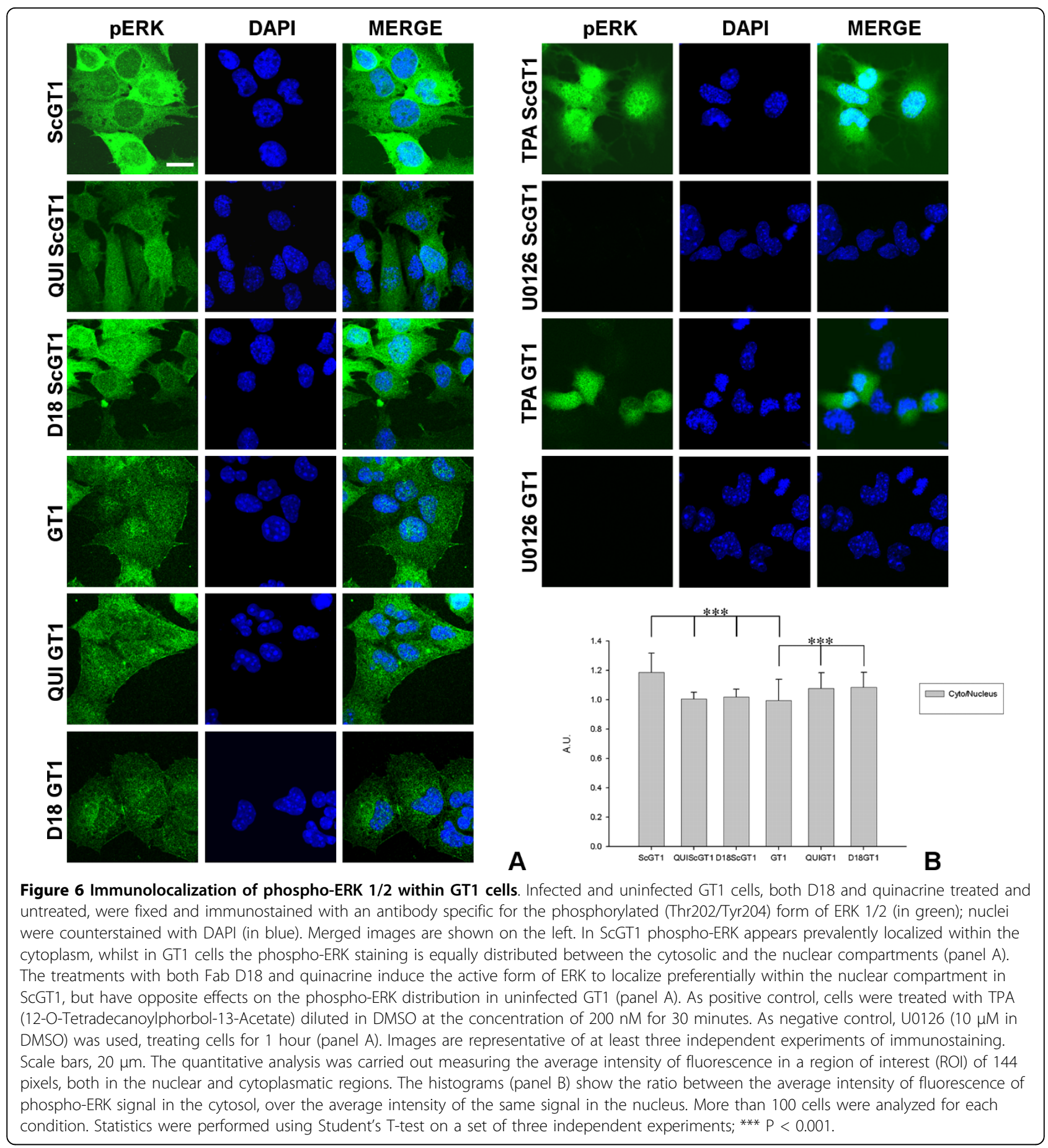

growth rate for the ScGT1 cells was found compared to uninfected cells (Fig. 7). Following treatment with Fab D18 $(50 \mathrm{nM})$ and quinacrine $(1 \mu \mathrm{M})$, cells were tested for proliferation, again in the presence of the two compounds at the same concentrations. MTT assay did not show any significant effects on cell growth of both ScGT1 and GT1 after the two treatments (Fig. 7).

\section{Discussion}

Prion infection hyper-stimulates ERK cascade

Whilst the pathological mechanism of prion diseases remains elusive, many lines of evidence indicate that prion infection may dramatically alter the physiology of the cell. Therefore, the focus of our work consisted in studying molecular signaling molecules in both healthy 


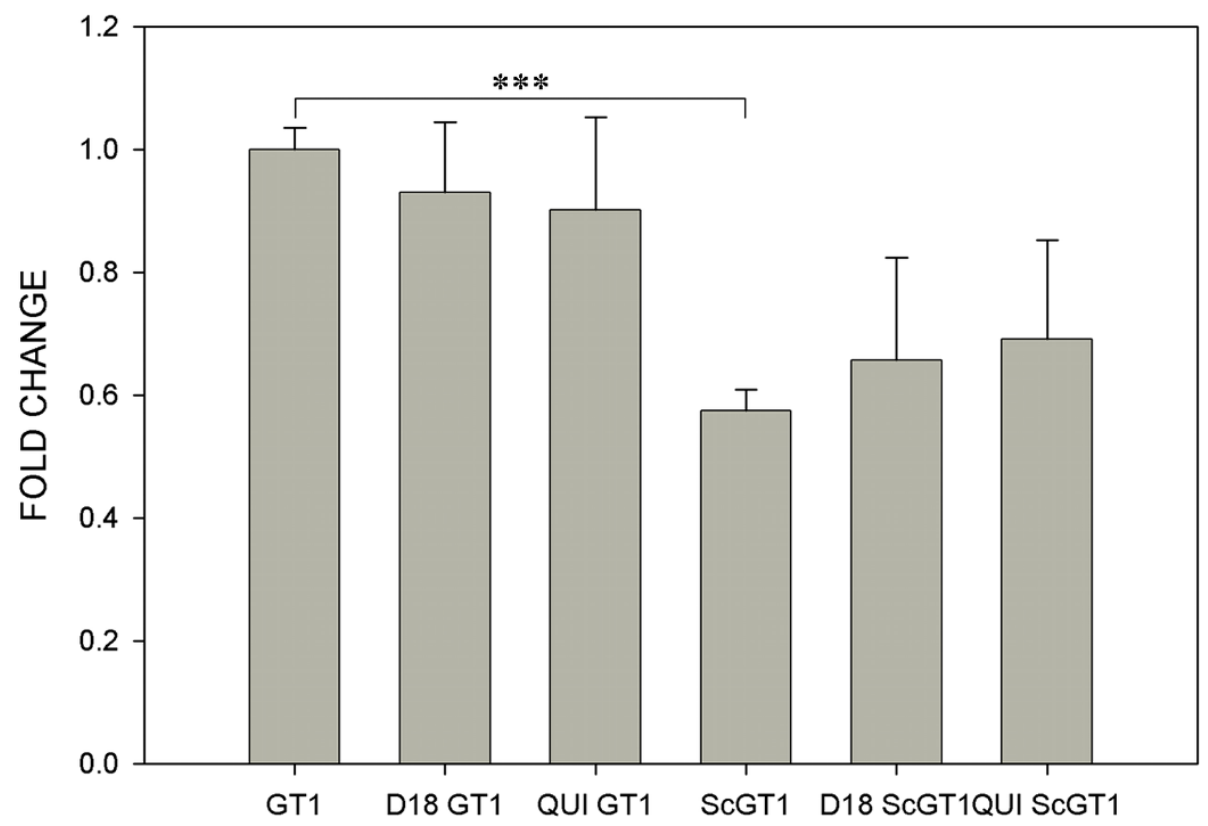

Figure 7 Scrapie infection affects cell proliferation. Cell proliferation was evaluated in ScGT1 and GT1 cells, pre-treated for 6 days with quinacrine $(1 \mu \mathrm{M})$ and Fab D18 (50 nM), over 4 days by means of MTT assay. Prion infection inhibits cell proliferation and both treatments seem to have no effect on it. Cell growth rate was calculated as described in Materials and Methods. All data come from three independent experiments performed each one in 5 replicates; they are expressed as mean value \pm SD. Statistics were performed using Student's T-test, *** $P<0.001$

and prion infected cells. We employed a well-known neuronal model, the murine immortalized hypothalamic GT1 cell line, able to sustain both de novo and chronic prion infection.

First, we analyzed the effect of prion infection in chronic infected cells. In particular, we assessed the ERK cascade, a pathway conserved throughout all classes of mammals and involved in processes such as cell growth, neuronal survival, axonal outgrowth and long-term plasticity $[29,30]$. The ERK pathway has been proposed as a possible target for TSE therapy since several tyrosine kinase inhibitors, such as STI571 and imatinib mesylate, have recently been shown to induce a complete clearance of $\mathrm{PrP}^{\mathrm{Sc}}$ in ScN2a cells and a decrease of its levels in scrapie-infected mouse spleens $[31,32]$. In addition, inhibitors of the MEK $1 / 2$ complex have proven to be efficient in clearing $\mathrm{PrP}^{\mathrm{Sc}}$ from ScGT1 cells [33]. Focusing on the three key nodes of ERK pathway, the src family, MEK1/2 and ERK1/2 complexes, we found that prion replication leads to a general hyper-activation of this cascade in GT1-1 cells. Interestingly, although we detected an increased level of phosphorylation for the ERK complex, we also found a lower level of activation of the MEK complex. We can speculate that this apparent paradox involves a different action of some phosphatases on ERK1/2 upon chronic prion infection.
We also examined the activation state of the pathway in de novo infected cells to assess the role of cloning selection in ERK signaling. We confirmed the activation of the pathway in GT1 cells upon prion infection, though the levels of phosphorylated proteins were not the same as for chronic infected cells. In this case we were able to detect increased levels for both phosphoMEK and phospho-ERK complexes in newly infected cells, but not for the src family. Most likely, since the antibody we used to detect src proteins recognizes all the 9 members of the family, the decrease in phosphosrc kinases may be explained considering the contributions of all the members of the family to the signal detected by Western blotting. In response to acute infection some members of the src family may undergo a massive negative regulation in terms of phosphorylation. While the src family member fyn seems to be the tyrosine kinase directly involved in the activation of the ERK pathway via PrP [17], other four members of the family (src, yes, lck and lyn) are expressed within the CNS and act on different substrates [34]. It has been shown that the tyrosine kinase inhibitor STI571 is able to block prion replication in scrapie-infected cells, promoting $\operatorname{PrP}^{\mathrm{Sc}}$ clearance throughout the lysosomal pathway [31]. Thus, it seems that the aberrant activation of src family proteins in chronically infected cells results in an impaired function of the lysosomal compartment, 
leading to $\operatorname{PrP}^{\mathrm{Sc}}$ accumulation. So, the negative regulation undergone by some members of the src family, when GT1 cells were exposed to prions in acute fashion, may be interpreted as a feedback response of the cell to induce $\operatorname{PrP}^{\mathrm{Sc}}$ catalysis. The self-propagating nature of prions and the foundation of a chronic infection in the long term, may lead to the loss of this cellular response, resulting in the aberrant activation of src kinases found in the ScGT1 cells.

\section{ERK retention within the cytoplasm: a possible cause for neurodegeneration?}

Taken together, these data may unveil at least one possible molecular mechanism responsible for neuronal loss upon prion infection. Besides the archetypical functions of the ERK cascade in cell survival and proliferation, recently a novel role in regulating cell death has emerged in neurodegenerative diseases. PhosphoERK aggregates were found in the substantia nigra of Parkinson's disease patients [35]. Elevated levels of phospho-ERK were also revealed in brain extracts of AD patients, but not in control individuals [36]. Moreover, a chronic activation of the ERK complex was detected in organotypic hippocampal slides from animal models for $A D$ overexpressing $A \beta$ [37]. In addition to the chronic activation of ERK, its localization within the cell seems to also play a crucial role in initiating neurodegenerative processes [38]. An intriguing scenario in which an aberrant activation of ERK, in kinetic and spatial terms, is linked to cell death processes seems to fit with our findings in GT1 cells, expanding our understanding of prion diseases. Both chronically and newly infected ScGT1 cells showed a persistent activation of ERK. Since prion conversion requires direct interaction between $\operatorname{PrP}^{\mathrm{C}}$ and $\mathrm{PrP}^{\mathrm{Sc}}$ most likely in the amyloidogenic domain (AGAAAAGA) of PrP (amino acids 109-122) [39], in ScGT1 cells prion replication may lead to aberrant signaling. Upon infection, the formation of multimeric structures of PrP, such as oligomers, may trigger the chronic activation of the ERK pathway. Immunocytochemistry data seem to provide support to our model. A different compartmentalization of phospho-ERK was described in infected and non-infected GT1 cells. While the active form of ERK seemed to be efficiently translocated in the nuclear compartment of uninfected cells, upon prion infection phospho-ERK appeared to be preferentially retained in the cytoplasm. Moreover, we showed how cell growth rate was lower in ScGT1 cells compared to uninfected cells. Tentatively, the impairment of nuclear translocation in infected cells may be correlated with the failed transcription of neuroprotective factors essential for cell survival and could explain the differences found in cell proliferation. In addition, upon prion infection in GT1 cells, a hyperphosphorylation of the S6 ribosomal protein has been described [40]. Since S6 protein is a target for the ERK complex, further studies are needed to assess whether the preferential localization of the active form of ERK in the cytoplasm of scrapie-infected ScGT1 can be also associated to the phosphorylation of $\mathrm{S} 6$ protein. The lack of gross pathological phenotype in ScGT1 could be explained by considering GT1 as active proliferating cells. Cell divisions may dilute the amount of $\operatorname{PrP} P^{S c}$ among daughter cells, minimizing marked pathological effects on cell physiology. In post-mitotic neuronal cells of the CNS, $\operatorname{PrP}^{\mathrm{Sc}}$ can accumulate and ultimately lead to neurodegeneration. This could explain why subpopulations of infected ScGT1 show reduced viability, with signs of neurodegeneration and vacuolation [41]. For some cells, where prion conversion rate is higher, the ERK pathway could be hyper-stimulated and detectable cellular damages may occur.

\section{Fab D18 and quinacrine treatments differently affect the ERK pathway}

The second aim of our study was to assess the effects on the ERK cascade induced by two molecules known to block prions. In recent years, much effort has been devoted to finding a molecule that would halt prion propagation. To date, two classes of compounds yielded promising results: small chemicals such as acridines [27] and antibodies, or antibody fragments, such as Fab D18 [26]. In our study, both infected and uninfected cells were treated with the two compounds to assess the effect on the activation of ERK pathway. Two main datasets emerged from our study, which revealed different effects on the ERK pathway when comparing infected and uninfected cells. Whilst the epitope for Fab D18 on PrP is well known [42], the binding surface on $\operatorname{PrP}$ for quinacrine is still debated. Moreover, the affinity of Fab D18 for PrP is much higher than for quinacrine; the dissociation constant for the quinacrine- $\operatorname{PrP}^{\mathrm{C}}$ complex is $4.6 \mathrm{mM}$ [43], whereas for the Fab D18- $\operatorname{PrP}^{\mathrm{C}}$ complex is $1.6 \mathrm{nM}$ [26]. Thus, the two compounds might act through different mechanisms. In particular quinacrine may interfere with prion replication through a process that does not require its binding to $\operatorname{PrP}^{\mathrm{C}}$, since the half-maximal $\mathrm{PrP}^{\mathrm{Sc}}$ inhibition occurs at effective concentrations $[\mathrm{EC}(50)]$ in the micromolar range [27]. Recent studies, for example, have shown acridines binding directly to $\mathrm{PrP}^{\mathrm{Sc}}[44]$. These data may also explain the differences found in terms of ERK pathway activation between infected and uninfected cells after treatment with the two compounds. Since Fab D18 carries on its inhibitory activity principally through binding to $\operatorname{PrP}^{C}$ and thus preventing its interaction with $\operatorname{PrP}^{\mathrm{Sc}}$, the effects on cell signaling are similar both in ScGT1 
and GT1 cells as they both share $\operatorname{PrP}^{\mathrm{C}}$ expression. On the contrary, quinacrine has a low affinity for $\operatorname{PrP}^{\mathrm{C}}$ and seems to block prion replication by binding and disrupting $\mathrm{PrP}^{\mathrm{Sc}}$ fibrils [45]. Large aggregates of $\mathrm{PrP}^{\mathrm{Sc}}$ are distinctive traits of infected cells, so it is reasonable that the effects of quinacrine treatment on the ERK pathway in infected and uninfected cells are very different. Alternatively, quinacrine might bind to protein(s) involved in prion replication, or may alter the biochemical environment necessary for template refolding. For many years the so-called "protein X" has been hypothesized to play an essential role in prion replication, a protein, maybe a chaperon, interacting with the $\operatorname{PrP}^{\mathrm{C}}-\mathrm{PrP}^{\mathrm{Sc}}$ complex and facilitating conversion. The binding of quinacrine to a key site of this putative molecule may alter its normal function in GT1 cells and interfere with the prion conversion process.

In addition, even though quinacrine and Fab D18 seem to maintain the physiological distribution of phospho-ERK in GT1 cells, both of them failed to revert ERK phosphorylation to physiological levels upon treatment of prion infected ScGT1. They also failed in rescuing the impaired cell proliferation detected in ScGT1 cells. These data could be explained considering that prion infection may alter some fundamental mechanism involved in cell division irreversibly. As an alternative, it could be hypothesized that the two treatments do not block prion replication completely, but just decrease it below the sensitivity of detection techniques. Moreover, the ability of the two molecules to alter the localization and the activation levels of ERK cascade in uninfected cells should be taken into consideration as a significant side effect in any therapeutic approach to prion disease.

The MEK inhibitor U0126 was also tested for its cell proliferation rescuing capacity in ScGT1 cells (see additional file 1). No significant differences in terms of cell growth were detected after 3 days of treatment, using a concentration of drug that completely inhibited the ERK complex phosphorylation $(10 \mu \mathrm{M})$ (see additional file 1). Thus, identifying a pharmacological treatment that not only clears prion infection, but also does not carry any apparent side effect on healthy cells, still remains a major challenge.

\section{Conclusions}

In this study we investigated the role of prion infection in ERK cascade signaling using a well-known neuronal model of prion replication. For the first time we were able to show a correlation between the aberrant activation of the ERK1/2 complex, its localization within the cytosolic compartment, and a lower growth rate in infected GT1 cells. Our findings indicate a possible mechanism of neurodegeneration that might explain the neuronal loss expressed upon prion disease onset. In addition, we tested two prion-curing compounds for their actions on the ERK pathway. The different responses observed may be correlated to different mechanisms of action.

\section{Materials and methods}

\section{Cell lines and cell culture}

GT1 and ScGT1 cells were maintained in Dulbecco's Modified Eagle's Medium with 4.5 g/L glucose (DMEM) (GIBCO/Invitrogen), supplemented with $10 \% \mathrm{v} / \mathrm{v}$ fetal bovine serum (GIBCO/Invitrogen) and antibiotics (100 $\mathrm{IU} / \mathrm{mL}$ penicillin and $100 \mathrm{mg} / \mathrm{mL}$ streptomycin) at $37^{\circ} \mathrm{C}$ in a humidified atmosphere with $5 \% \mathrm{CO}_{2}$. All cell lines were kindly provided by Dr. P. Mellon (The Salk Institute, La Jolla, CA, USA). Scrapie cells were chronically infected with Rocky Mountain Lab (RML) prion strain according to already published procedures.

\section{De novo prion infection}

ScGT1 cells were grown at confluence and fixed in paraformaldehyde $4 \%$ in PBS for 20 min at room temperature (RT). Then, the cell layer was washed in PBS three times and permeabilized with TRITON XT-100 0.1\% in PBS for 15 min. After further washings with PBS, GT1 cells were cultured on this "infective layer" for 1 week, refreshing the medium on the third day. Then cells were split 1:3 for three times and tested at the fourth passage. Cells were grown on fixed GT1 cells as control.

\section{Antibodies}

The monoclonal antibodies against the phosphorylated and non-phosphorylated forms of the src family [Src Family Antibody \#2109 and phospho-Src Family (Tyr416) antibody \#2101), MEK1/2 (MEK1/2 Antibody \#9122 and phospho-MEK1/2 (Ser217/221) (41G9) rabbit $\mathrm{mAb}$ \#9154] and ERK 1/2 [p42 MAP Kinase (3A7) mouse mAb \#9107 and phospho-p44/42 Map Kinase (Thr202/Tyr204) Ab \#9101] were purchased from Cell Signaling Technology. The Fab D18 fragment raised against PrP was purchased from InPro Biotech.

\section{Preparation of cytosolic extracts}

Cells were treated for 6 days with Fab D18 (50 nM), or quinacrine (Fluka), which had been dissolved in PBS (1 $\mu \mathrm{M})$. The medium was refreshed after 3 days. Cells were then washed twice with cold PBS $1 \times(\mathrm{GIBCO} /$ Invitrogen) and incubated for $10 \mathrm{~min}$ on ice, in lysis buffer [ $50 \mathrm{mM}$ Tris- $\mathrm{HCl}(\mathrm{pH}$ 7.4) $150 \mathrm{mM} \mathrm{NaCl}, 1 \%$ Triton X-100, $2 \mathrm{mM} \mathrm{Na}_{3} \mathrm{VO}_{4}$ and a mixture of protease inhibitors (Roche)]. The cell extracts were then centrifuged at 2,300 $\mathrm{g}$ for $5 \mathrm{~min}$. The supernatant was stored at $-80^{\circ} \mathrm{C}$ before being used. Total protein concentration was determined using the bicinchoninic acid assay (Pierce). 


\section{Proteinase $\mathrm{K}$ digestion assay}

Cells were washed twice with cold PBS $1 \times(\mathrm{GIBCO} / \mathrm{Invi}-$ trogen) and lysed with lysis buffer $(10 \mathrm{mM}$ Tris- $\mathrm{HCl} \mathrm{pH}$ 8.0, $150 \mathrm{mM} \mathrm{NaCl}, 0.5 \%$ nonidet P-40 substitute, $0.5 \%$ deoxycholic acid sodium salt) and pelleted by centrifugation at 2,300 g for $5 \mathrm{~min}$. The supernatant was collected and the total protein concentration measured using bicinchoninic acid assay (Pierce). For the assay, $250 \mu \mathrm{g}$ of protein was treated with $5 \mu \mathrm{g}$ proteinase $\mathrm{K}$ (Roche, ratio protein:protease 50:1) for 1 hour at $37^{\circ} \mathrm{C}$. Digestion was stopped by the addition of phenylmethyl sulphonyl fluoride to a final concentration of $2 \mathrm{mM}$. The PrP was precipitated by ultracentrifugation at $100,000 \mathrm{~g}$ (Optima TL, Beckman) for 1 hour at $4^{\circ} \mathrm{C}$. After centrifugation, the supernatant was discarded and the pellet resuspended in loading buffer $1 \mathrm{X}$, before loading onto a $12 \%$ SDS-PAGE. Samples were electroblotted onto membranes of polyvinylidene fluoride (PVDF). PVDF membranes were blocked with $5 \%(\mathrm{w} / \mathrm{v})$ non-fat milk protein in TBS-T $(0.05 \%$ Tween) for 1 hour at RT. Membranes were incubated in $1 \mu \mathrm{g} / \mathrm{mL}$ of Fab D18 in $1 \times$ PBS for 2 hours at RT; before incubation for 1 hour, in the secondary antibody, goat-anti-human HRP-conjugated (Pierce), at 1:5000 diluted in 5\% (w/v) non-fat milk protein in TBS-T. After several washes, the signal was detected using ECL kit (Amersham Pharmacia) on ECL Hypermax films (Amersham Pharmacia).

\section{Western blot assay}

An amount equal to $25 \mu \mathrm{g}$ of total proteins was separated by $12 \%$ SDS-PAGE and transferred to PVD membranes (Millipore). These were then blocked in 5\% non-fat dried milk in TBS-T (0.05\% Tween) for 1 hour at RT before incubation overnight at $4{ }^{\circ} \mathrm{C}$ with primary antibody $(1: 1,000$ or $1: 2,000)$ diluted in $5 \%$ non-fat dried milk or $5 \%$ bovine serum albumin. After 3 washes in TBS-T, the membranes were incubated for 1 hour at RT in secondary antibody, goat-anti-mouse or rabbit, HRP-conjugated $(1: 2,000)$ diluted in $5 \%$ non-fat dried milk in TBS-T. The chemiluminescent signal was detected using ECL kit (Amersham Pharmacia) on ECL Hypermax films (Amersham Pharmacia). Densitometric analysis was performed using a Molecular Imager ChemiDoc XRS System equipped with Quantity One software (Biorad).

\section{Thiazolyl blue tetrazolium bromide (MTT) cell growth assay}

ScGT1 and GT1 cells were treated with quinacrine $(1 \mu \mathrm{M})$ and Fab D18 (50 nM) for 6 days. Then, about 30,000 cells per well were cultured, again in the presence of the two compounds at the same concentrations in a 96-well, tissue culture-treated plate for 4 days, measuring cell proliferation each day. To study the effects of the MEK inhibitor U0126 (Promega) on cell growth, ScGT1 and GT1 cells were seeded in a 96-well, tissue culture-treated plate and treated with U0126 $(10 \mu \mathrm{M})$ diluted in dimethyl sulfoxide (DMSO) for 3 days. DMSO alone was used as control. In all conditions tested, every 24 hours the medium was removed and the cells were incubated with $150 \mu \mathrm{L}$ of MTT (Sigma) working solution $(0.5 \mathrm{mg} / \mathrm{mL}$ of MTT in sterile PBS) for 2 hours at $37^{\circ} \mathrm{C}$. The solution was removed and formazan was solubilized adding $150 \mu \mathrm{L}$ of DMSO to each well. The optical density was read at $560 \mathrm{~nm}$ and the background subtracted at $670 \mathrm{~nm}$ using a VersaMax plate reader (Molecular Device). Growth rate was calculated dividing the absorbance value of the last day with the value measured on the first.

\section{Immunofluorescence assay}

Treated and untreated cells were grown overnight on glass coverslips coated with poly-L-lysine $(10 \mu \mathrm{g} / \mathrm{mL})$ before fixation in paraformaldehyde $4 \%$ in PBS for 20 min at RT. The cells were blocked for 1 hour at RT, in $10 \%$ normal goat serum (VECTOR Laboratories) diluted in PBS with $0.3 \%$ Triton X-100. After blocking, cells were incubated at $4^{\circ} \mathrm{C}$ overnight with primary antibody in dilution buffer ( $1 \%$ bovine serum albumin in PBS with $0.3 \%$ Triton X-100). Coverslips were washed 2 times in PBS and given an additional third washing in high-salt PBS for 2 min to decrease the aspecific binding of the antibody. After an additional wash with PBS alone, cells were further incubated for 1 hour at RT in the dark with secondary antibody, conjugated with AlexaFluor 488 (1:500; Invitrogen) in dilution buffer. Cells were further washed as described above, before mounting on Vectashield with DAPI (VECTOR Laboratories). Images were acquired with a DMIR2 confocal microscope equipped with Leica Confocal Software (Leica).

\section{Fluorescence quantification}

In order to quantify the fluorescence in the cytosolic and nuclear compartments, random fields for each tested condition were taken at the same magnification $(40 \times$, zoom $4 \times)$. Then, a region of interest (ROI) with an area of 144 pixels $(12 \times 12)$ was chosen, and the average intensity of fluorescence within the ROI was measured in the nucleus and cytosol of every cell present in the field. More than 100 cells for every condition were analyzed. The values obtained were averaged, and the ratios between the mean value for the cytosol and the mean value for the nucleus were plotted in a histogram graph. Images were analyzed with ImageJ open source software http://rsbweb.nih.gov/ij/index.html. The results were obtained from three independent experiments. 


\section{Statistical analysis}

Student's $\mathrm{t}$ test was used to determine significant differences among the src family, MEK $1 / 2$, ERK $1 / 2$ phosphorylation, among prion infected and uninfected, and between Fab D18 treated and quinacrine treated cell lines. The levels of phosphorylation for every protein were normalized to the total amount of the same protein. All data are expressed as mean value \pm SD and the values of controls are adjusted to 1 ; each resulting value was determined by averaging three independent experiments.

\section{Additional material}

\section{Additional file 1: MEK inhibitor U0126 has no effect on cell} proliferation. ScGt1 and GT1 cells were treated for 3 days with MEK inhibitor (10 $\mu \mathrm{M}$ in DMSO) and its effects on cell proliferation were evaluated by means of MTT assay. The inhibitory effect on MEK phosphorylation at the concentration used was tested by Western blot (A). A complete inhibition of MEK phosphorylation was detected already after 1 hour of treatment with U0126 (10 $\mu \mathrm{M})$ both in ScGT1 and GT1. The treatment conducted over 3 days on infected and uninfected cells had no statistically significant effect on cell proliferation (B). Cell growth rate was calculated as described in the Materials and Methods section. All data come from three independent experiments performed each one in 5 replicates; they are expressed as mean value \pm SD

\begin{abstract}
Abbreviations used
PrP: prion protein; $\operatorname{PrP}^{C}$ : cellular form of PrP; $\operatorname{PrP}^{\mathrm{Sc}}$ : scrapie isoform of PrP; N2a: mouse neuroblastoma cell line; ScN2a: scrapie-infected N2a; GT1: mouse hypothalamic cell line; ScGT1: scrapie-infected GT1; PK: proteinase K; MAPK: mitogen activated protein kinase; MEK: MAP and ERK kinases; ERK: extracellular regulated kinase.
\end{abstract}

\section{Acknowledgements}

This work was supported by grants to GL from the Fondazione Compagnia di San Paolo and the Ministero della Salute. The authors wish to thank Gabriella Furlan for editing and proofreading the manuscript.

\section{Author details}

${ }^{1}$ Laboratory of Prion Biology, Neurobiology Sector, Scuola Internazionale Superiore di Studi Avanzati (SISSA), via Bonomea 265, I-34136 Trieste, Italy. ${ }^{2}$ ELETTRA Laboratory, Sincrotrone Trieste S.C.p.A., S.S. 14 Km 163.5, I-34149 Basovizza (TS), Trieste, Italy. ${ }^{3}$ Italian Institute of Technology, SISSA Unit, via Bonomea 265, I-34136 Trieste, Italy.

\section{Authors' contributions}

AD designed, carried out all the experiments and drafted the manuscript. GL designed the study and drafted the manuscript. All authors read and approved the manuscript.

\section{Competing interests}

The authors declare that they have no competing interests.

Received: 9 March 2010 Accepted: 9 August 2010 Published: 9 August 2010

\section{References}

1. Prusiner SB: Novel proteinaceous infectious particles cause scrapie. Science 1982, 216:136-144.

2. Prusiner SB: Prions. Proc Natl Acad Sci USA 1998, 95:13363-13383.

3. Bueler H, Fischer M, Lang Y, Bluethmann H, Lipp HP, DeArmond SJ, Prusiner SB, Aguet M, Weissmann C: Normal development and behaviour of mice lacking the neuronal cell-surface PrP protein. Nature 1992, 356:577-582

4. Brown DR, Qin K, Herms JW, Madlung A, Manson J, Strome R, Fraser PE, Kruck T, von Bohlen A, Schulz-Schaeffer $W$, et al: The cellular prion protein binds copper in vivo. Nature 1997, 390:684-687.

5. Schmitt-Ulms G, Legname G, Baldwin MA, Ball HL, Bradon N, Bosque PJ, Crossin KL, Edelman GM, DeArmond SJ, Cohen FE, Prusiner SB: Binding of neural cell adhesion molecules (N-CAMs) to the cellular prion protein. $J$ Mol Biol 2001, 314:1209-1225.

6. Hundt C, Peyrin JM, Haik S, Gauczynski S, Leucht C, Rieger R, Riley ML, Deslys JP, Dormont D, Lasmezas Cl, Weiss S: Identification of interaction domains of the prion protein with its $37-\mathrm{kDa} / 67-\mathrm{kDa}$ laminin receptor. EMBO J 2001, 20:5876-5886.

7. Kanaani J, Prusiner SB, Diacovo J, Baekkeskov S, Legname G: Recombinant prion protein induces rapid polarization and development of synapses in embryonic rat hippocampal neurons in vitro. J Neurochem 2005, 95:1373-1386.

8. Rogivue C, Gottwein J, Aguzzi A, Glatzel M: [Transmissible spongiform encephalopathies in humans]. Schweiz Arch Tierheilkd 2002, 144:685-690.

9. Lopes MH, Hajj GN, Muras AG, Mancini GL, Castro RM, Ribeiro KC, Brentani RR, Linden R, Martins VR: Interaction of cellular prion and stressinducible protein 1 promotes neuritogenesis and neuroprotection by distinct signaling pathways. J Neurosci 2005, 25:11330-11339.

10. Chiarini LB, Freitas AR, Zanata SM, Brentani RR, Martins VR, Linden R: Cellular prion protein transduces neuroprotective signals. EMBO J 2002, 21:3317-3326.

11. Fuhrmann $M$, Bittner $T$, Mitteregger $G$, Haider $N$, Moosmang $S$, Kretzschmar $\mathrm{H}$, Herms J: Loss of the cellular prion protein affects the Ca2 + homeostasis in hippocampal CA1 neurons. J Neurochem 2006, 98:1876-1885

12. Herms JW, Korte S, Gall S, Schneider I, Dunker S, Kretzschmar HA: Altered intracellular calcium homeostasis in cerebellar granule cells of prion protein-deficient mice. J Neurochem 2000, 75:1487-1492.

13. Kristensson K, Feuerstein B, Taraboulos A, Hyun WC, Prusiner SB, DeArmond SJ: Scrapie prions alter receptor-mediated calcium responses in cultured cells. Neurology 1993, 43:2335-2341.

14. Lauren J, Gimbel DA, Nygaard HB, Gilbert JW, Strittmatter SM: Cellular prion protein mediates impairment of synaptic plasticity by amyloidbeta oligomers. Nature 2009, 457:1128-1132.

15. Whitmarsh AJ, Davis RJ: Signal transduction by MAP kinases: regulation by phosphorylation-dependent switches. SCi STKE 1999, 1999:PE1.

16. Chang $L$, Karin M: Mammalian MAP kinase signalling cascades. Nature 2001, 410:37-40.

17. Mouillet-Richard S, Ermonval M, Chebassier C, Laplanche JL, Lehmann S, Launay JM, Kellermann O: Signal transduction through prion protein. Science 2000, 289:1925-1928.

18. Monnet C, Gavard J, Mege RM, Sobel A: Clustering of cellular prion protein induces ERK1/2 and stathmin phosphorylation in GT1-7 neuronal cells. FEBS Lett 2004, 576:114-118.

19. Krebs B, Dorner-Ciossek C, Schmalzbauer R, Vassallo N, Herms J, Kretzschmar HA: Prion protein induced signaling cascades in monocytes. Biochem Biophys Res Commun 2006, 340:13-22.

20. Lee HP, Jun YC, Choi JK, Kim Jl, Carp Rl, Kim YS: Activation of mitogenactivated protein kinases in hamster brains infected with $263 \mathrm{~K}$ scrapie agent. J Neurochem 2005, 95:584-593.

21. Nixon RR: Prion-associated increases in Src-family kinases. J Biol Chem 2005, 280:2455-2462

22. Uppington KM, Brown DR: Resistance of cell lines to prion toxicity aided by phospho-ERK expression. J Neurochem 2008, 105:842-852.

23. Pietri M, Caprini A, Mouillet-Richard S, Pradines E, Ermonval M, Grassi J, Kellermann O, Schneider B: Overstimulation of PrPC signaling pathways by prion peptide 106-126 causes oxidative injury of bioaminergic neuronal cells. J Biol Chem 2006, 281:28470-28479.

24. Gotz ME, Kunig G, Riederer P, Youdim MB: Oxidative stress: free radical production in neural degeneration. Pharmacol Ther 1994, 63:37-122.

25. Mellon PL, Windle JJ, Goldsmith PC, Padula CA, Roberts JL, Weiner Rl: Immortalization of hypothalamic $\mathrm{GnRH}$ neurons by genetically targeted tumorigenesis. Neuron 1990, 5:1-10.

26. Peretz D, Williamson RA, Kaneko K, Vergara J, Leclerc E, Schmitt-Ulms G, Mehlhorn IR, Legname G, Wormald MR, Rudd PM, et al: Antibodies inhibit 
prion propagation and clear cell cultures of prion infectivity. Nature 2001, 412:739-743.

27. Korth C, May BC, Cohen FE, Prusiner SB: Acridine and phenothiazine derivatives as pharmacotherapeutics for prion disease. Proc Natl Acad Sci USA 2001, 98:9836-9841.

28. Vilette D: Cell models of prion infection. Vet Res 2008, 39:10.

29. Grewal SS, York RD, Stork PJ: Extracellular-signal-regulated kinase signalling in neurons. Curr Opin Neurobiol 1999, 9:544-553.

30. Xiao J, Liu Y: Differential roles of ERK and JNK in early and late stages of neuritogenesis: a study in a novel PC12 model system. J Neurochem 2003, 86:1516-1523.

31. Ertmer A, Gilch S, Yun SW, Flechsig E, Klebl B, Stein-Gerlach M, Klein MA, Schatzl HM: The tyrosine kinase inhibitor ST1571 induces cellular clearance of PrPSc in prion-infected cells. J Biol Chem 2004, 279:41918-41927.

32. Yun SW, Ertmer A, Flechsig E, Gilch S, Riederer P, Gerlach M, Schatzl HM, Klein MA: The tyrosine kinase inhibitor imatinib mesylate delays prion neuroinvasion by inhibiting prion propagation in the periphery. Neurovirol 2007, 13:328-337.

33. Nordstrom EK, Luhr KM, Ibanez C, Kristensson K: Inhibitors of the mitogenactivated protein kinase kinase $1 / 2$ signaling pathway clear prioninfected cells from PrPSc. J Neurosci 2005, 25:8451-8456.

34. Kalia LV, Gingrich JR, Salter MW: Src in synaptic transmission and plasticity. Oncogene 2004, 23:8007-8016.

35. Zhu JH, Kulich SM, Oury TD, Chu CT: Cytoplasmic aggregates of phosphorylated extracellular signal-regulated protein kinases in Lewy body diseases. Am J Pathol 2002, 161:2087-2098.

36. Russo C, Dolcini V, Salis S, Venezia V, Zambrano N, Russo T, Schettini G: Signal transduction through tyrosine-phosphorylated C-terminal fragments of amyloid precursor protein via an enhanced interaction with Shc/Grb2 adaptor proteins in reactive astrocytes of Alzheimer's disease brain. J Biol Chem 2002, 277:35282-35288.

37. Dineley KT, Westerman M, Bui D, Bell K, Ashe KH, Sweatt JD: Beta-amyloid activates the mitogen-activated protein kinase cascade via hippocampal alpha7 nicotinic acetylcholine receptors: In vitro and in vivo mechanisms related to Alzheimer's disease. J Neurosci 2001, 21:4125-4133.

38. Colucci-D'Amato L, Perrone-Capano C, di Porzio U: Chronic activation of ERK and neurodegenerative diseases. Bioessays 2003, 25:1085-1095.

39. Holscher C, Delius H, Burkle A: Overexpression of nonconvertible PrPc delta114-121 in scrapie-infected mouse neuroblastoma cells leads to trans-dominant inhibition of wild-type PrP(Sc) accumulation. J Virol 1998, 72:1153-1159.

40. Nordstrom E, Fisone G, Kristensson K: Opposing effects of ERK and p38JNK MAP kinase pathways on formation of prions in GT1-1 cells. Faseb J 2009, 23:613-622.

41. Schätzl HM, Laszlo L, Holtzman DM, Tatzelt J, DeArmond SJ, Weiner RI, Mobley WC, Prusiner SB: A hypothalamic neuronal cell line persistently infected with scrapie prions exhibits apoptosis. J Virol 1997, 71:8821-8831.

42. Williamson RA, Peretz D, Pinilla C, Ball H, Bastidas RB, Rozenshteyn R, Houghten RA, Prusiner SB, Burton DR: Mapping the prion protein using recombinant antibodies. J Virol 1998, 72:9413-9418.

43. Vogtherr M, Grimme S, Elshorst B, Jacobs DM, Fiebig K, Griesinger C, Zahn R: Antimalarial drug quinacrine binds to C-terminal helix of cellular prion protein. J Med Chem 2003, 46:3563-3564.

44. Phuan PW, Zorn JA, Safar J, Giles K, Prusiner SB, Cohen FE, May BC: Discriminating between cellular and misfolded prion protein by using affinity to 9-aminoacridine compounds. J Gen Virol 2007, 88:1392-1401.

45. Barret A, Tagliavini F, Forloni G, Bate C, Salmona M, Colombo L, De Luigi A, Limido L, Suardi S, Rossi G, et al: Evaluation of quinacrine treatment for prion diseases. J Virol 2003, 77:8462-8469.

doi:10.1186/1750-1326-5-29

Cite this article as: Didonna and Legname: Aberrant ERK 1/2 complex activation and localization in scrapie-infected GT1-1 cells. Molecular Neurodegeneration 2010 5:29.

\section{Submit your next manuscript to BioMed Central and take full advantage of:}

- Convenient online submission

- Thorough peer review

- No space constraints or color figure charges

- Immediate publication on acceptance

- Inclusion in PubMed, CAS, Scopus and Google Scholar

- Research which is freely available for redistribution

Submit your manuscript at www.biomedcentral.com/submit 